\title{
Tolerance, safety and accuracy of stress cardiovascular magnetic resonance in routine clinical practice
}

\author{
Jeffrey Khoo*, Benjamin J Grundy, Miroslav J Munclinger, Christopher D Steadman, Natalie Austin, \\ Emer P Sonnex, Richard A Coulden, Gerald P McCann
}

From 2011 SCMR/Euro CMR Joint Scientific Sessions

Nice, France. 3-6 February 2011

\section{Background/Aim}

The use of stress cardiac magnetic resonance (CMR) as a clinical tool to evaluate myocardial ischaemia has increased significantly over recent years, but large-scale audit data is lacking. We therefore aimed to assess the tolerance, safety and accuracy of stress CMR in routine clinical practice.

\section{Methods}

We retrospectively examined all stress CMR studies performed at our tertiary referral centre over a 20-month period, since the service was started in 2007. Patients were scanned in a $1.5 \mathrm{~T}$ magnet (Avanto, Siemens), using a standardised protocol with routine imaging for late gadolinium enhancement (LGE). They were screened for contraindications to adenosine, and routine anti-anginal therapies, including beta-blockers, were not discontinued. Dobutamine stress was given in small number of patients in whom adenosine was contraindicated. Angiograms of patients who also had cardiac catheterization within 6 months of their CMR scan, were reassessed by an interventional cardiologist, blinded to the CMR data. For receiver-operator curve (ROC) analysis, CMR stress perfusion defects were graded into 5 categories (normal, probably normal, possibly abnormal, probably abnormal, abnormal).

\section{Results}

A total of 654 patients were scanned. The mean age was $65 \pm 29$ years, and there were 63 inpatients $(9.6 \%)$. The majority (639 patients; $97.7 \%$ ) received intravenous adenosine $(140 \mathrm{mcg} / \mathrm{kg} / \mathrm{min}$ for average of 3 minutes), 10 received

University Hospitals of Leicester NHS Trust, Leicester, UK intravenous dobutamine and 5 patients had both. Of the 15 patients who received dobutamine, 12 had no side effects/complications, 2 experienced nausea, and 1 chest tightness. Tolerance and safety data for all 644 patients who received adenosine are shown in Table 1.

241 patients also had coronary angiography. ROC analysis for detecting significant stenoses of $>70 \%$ is shown in figure 1.

\section{Conclusion}

We conclude that stress CMR, with adenosine as the main stress agent, is well-tolerated, safe and accurate in routine clinical practice.

Published: 2 February 2011

Table 1

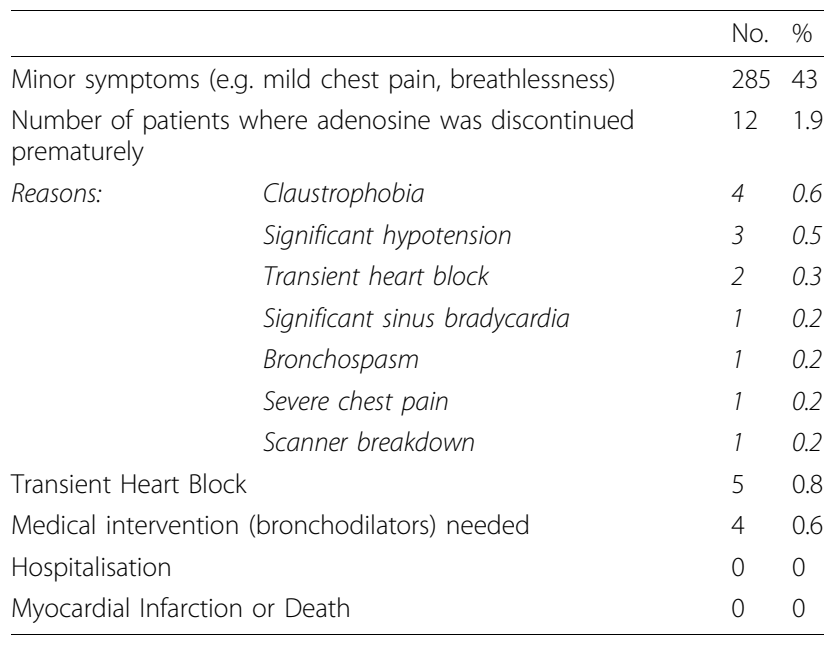




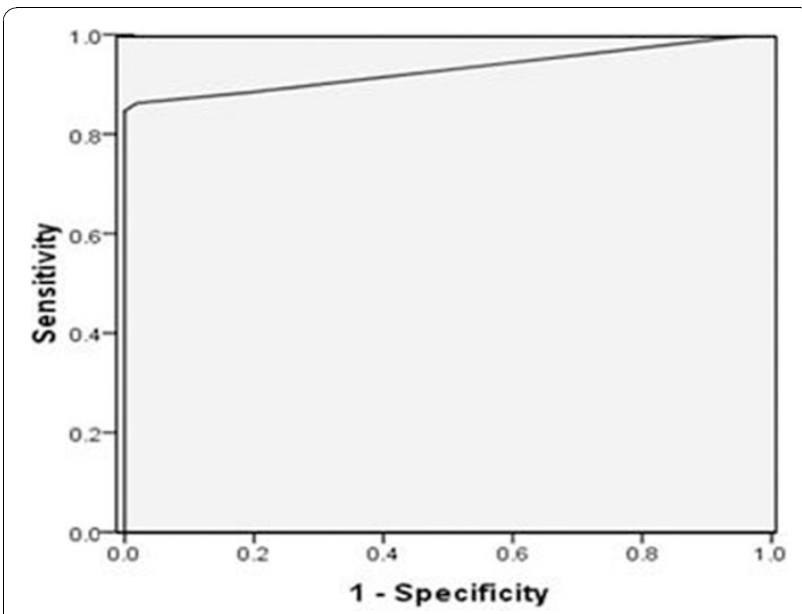

Figure 1 The area under curve $(A \cup C)$ is $0.91 \pm 0.02$, with a prevalence of $71 \%$. The overall sensitivity is $91 \%$, specificity $86 \%$, and accuracy $90 \%$. These results compare very favourably with previous smaller research studies and meta-analyses.

doi:10.1186/1532-429X-13-S1-P79

Cite this article as: Khoo et al.: Tolerance, safety and accuracy of stress cardiovascular magnetic resonance in routine clinical practice. Journal of Cardiovascular Magnetic Resonance 2011 13(Suppl 1):P79.

Submit your next manuscript to BioMed Central and take full advantage of:

- Convenient online submission

- Thorough peer review

- No space constraints or color figure charges

- Immediate publication on acceptance

- Inclusion in PubMed, CAS, Scopus and Google Scholar

- Research which is freely available for redistribution

Submit your manuscript at www.biomedcentral.com/submit 